\title{
Caregivers Adherence to the WHO Breastfeeding Guideline and Nutritional Status of Children under Five Years in Northern Region of Ghana
}

\author{
Barma Laribick Dujin \\ Department of Public Health, School of Allied Health Sciences, University for Development Studies, Ghana. \\ Post Office Box TL 1883-Tamale Campus
}

\begin{abstract}
The main aim of the study was to assess feeding practices and nutritional status of children under five years. The study also examined caregivers' adherence to the WHO breastfeeding and introduction of solid foods and semisolid foods at six months guidelines and the nutritional status of children under five years in the Northern Region of Ghana. Descriptive survey with cross sectional design was employed with the use of multi stage sampling technique at Child Welfare Clinics to obtain 495 caregivers-child pairs for the study. A structured questionnaire was employed to obtain the primary data and charts, tables, texts were employed to present the primary data. Descriptive and inferential statistics were employed in analysing data and the results presented in charts and tables. Overall, $25.3 \%$ of 495 infants had been exclusively breastfed for 6 months. There was a significant relationship between caregivers educational level and adherence to breastfeeding guidelines $(\mathrm{P}=0.004)$. From the results, $30.7 \%$ of the children were underweight, $20.2 \%$ of them being wasted and $43.0 \%$ and $8.7 \%$ respectively being stunted and overweight. Intensive health education by health workers should be done to improve good nutrition in the study areas.
\end{abstract}

Keywords: Caregivers, Adherence, Breastfeeding, Guidelines and Nutrition

DOI: $10.7176 /$ FSQM/86-08

Publication date: April $30^{\text {th }} 2019$

\section{Introduction}

Inappropriate feeding practices during the first five years of life are a major cause of malnutrition in young children. Thus, growth faltering and nutritional deficiencies continue to be highly prevalent in infants and young children living in low and middle income countries (UNICEF, 2014). Children under 5 years of age are often at risk for malnutrition because this is a period of rapid growth and development characterised by changes in body size and composition and increased physical activity. The consequences of malnutrition are severe and long lasting when it occurs at the early stage (Spinks \& Hamilton, 2015).

According to GSS (2014), the Northern Region recorded the highest stunting rate in Ghana for both moderate and severe stunting as $43.8 \%$ with underweight and wasting levels as high as $29.6 \%$ and $9.2 \%$ respectively.

One potential way of dealing with poor nutrition that WHO has recommended is exclusive breastfeeding for infants during their first six months of life and continuation of breastfeeding for up to two years (WHO, 2014). The WHO and UNICEF global strategy for infant and young child feeding articulates the need to focus attention on the effects of feeding practices on child growth (WHO, 2014). Although these feeding recommendations were based on evidence available in the published literature, the effects of following these recommended infant feeding practices (IFPs) on growth during infancy and early childhood have not been adequately studied ( WHO, 2014).

Further review of literature in Ghana since 2007 showed that published works in malnutrition studies revealed that the Savelugu/Nanton Municipality has one of highest malnutrition rates in the Northern Region of Ghana and the Bunkpurugu/Yunyoo recording one of the lowest malnutrition rates (GSS, 2007; GHS, 2016). This informs the researcher's decision to select the two districts out of the 26 districts for the present study.

The purpose of this paper was to assess how caregivers adhered to the WHO guidelines on breastfeeding and solid/semi solid food introduction at six months and their influence on the nutritional status of children under five years in the Northern Region of Ghana.

\subsection{MATERIALS AND METHODS}

\subsection{Study Area}

The study focused on the Northern Region of Ghana with the selection of the Savelugu Nanton Municipality and Bunkpurugu/Yunyoo District of the Northern Region of Ghana. The selection of the region and the districts were as a result of their malnutrition characteristics. For instance, the Northern Region had the highest malnutrition rates in Ghana (GSS, 2011; GSS, 2014) and the Savelugu/Nanton had the highest rates of malnutrition and the Bunkpurugu/Yunyoo had the lowest rates of malnutrition in the Northern Region (GSS, 2007; GHS, 2016). 


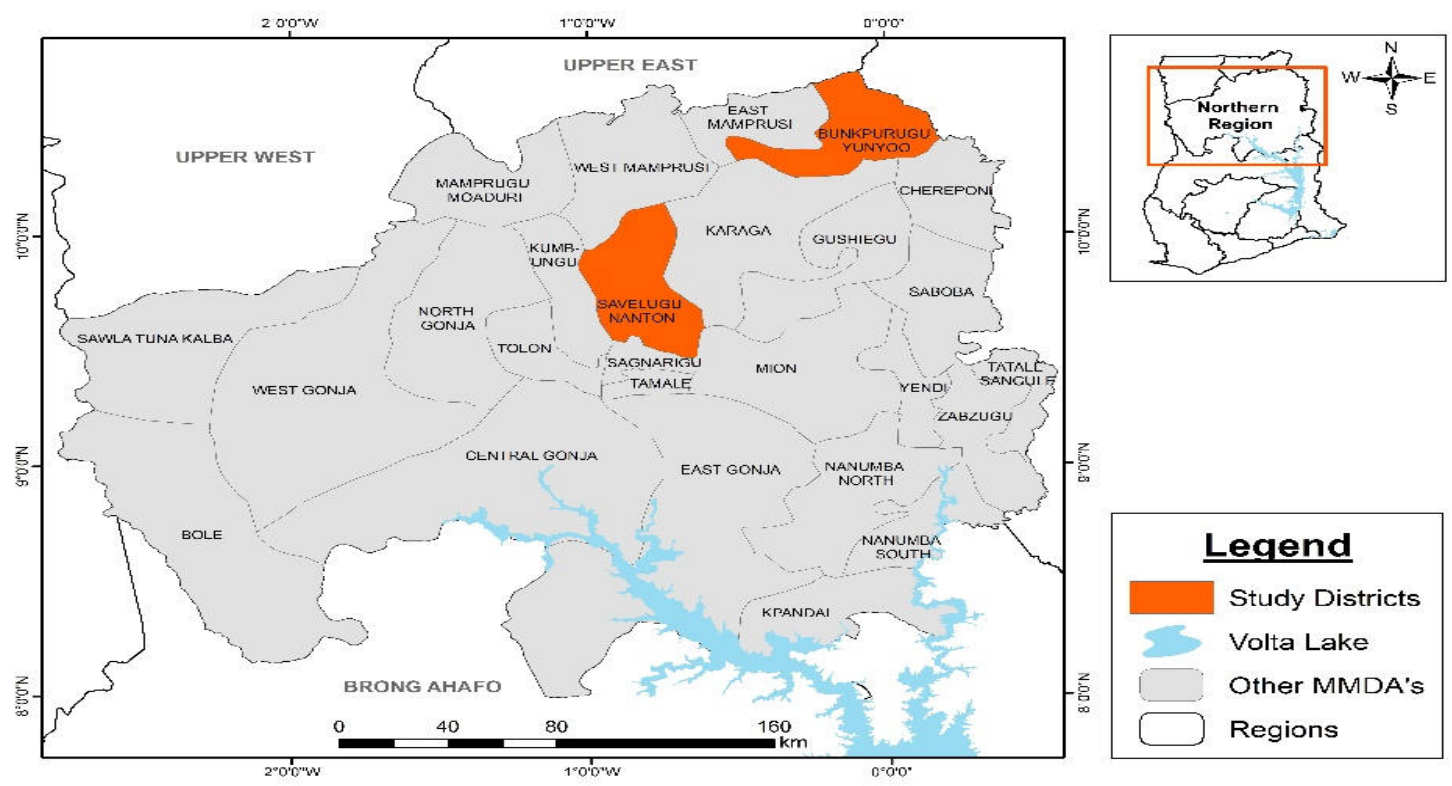

Figure 1. Map of the Northern Region of Ghana showing the study districts

\subsection{Research Design and Philosophy}

The descriptive cross sectional study design was employed to explain the prevalence of malnutrition attributable by caregivers' adherence to WHO breastfeeding and the introduction of solid/ semi-solid foods guidelines. The positivist view is used here as the guiding paradigm supporting the study. Positivism belongs to the epistemology which can be specified as philosophy of knowing, thus, positivism adheres to the view that only "factual" knowledge gained through observation (the senses), including measurement is trustworthy.

\subsection{Sample Size Determination}

Adapting the Ghana Demographic Health Survey (GSS, GHS \& ICF Macro, 2015) single proportion formula for calculating sample sizes with an average prevalence of underweight, the sample size is calculated by the formula: $\mathrm{n}=\mathrm{Z}^{2} \mathrm{p}(1-\mathrm{p})$

\section{$\mathrm{d}^{2}$}

where $\mathrm{Z}$-value at $95 \% \mathrm{CI}=1.96$ and $\mathrm{d}=$ the margin of error $=0.05$ and $\mathrm{p}=$ prevalence of underweight in Ghana using GDHS 2014=20\%

$\mathrm{n}=\left(1.96^{2} \mathrm{x} 0.20\right)(1-0.20)$

\section{$0.05^{2}$}

$\mathrm{n}=245$ multiplied by a constant design effect of 2

$\mathrm{n}=245 \mathrm{x}$ design effect of $2=490$.

To derive the actual sample size, a rate of $10 \%$ is calculated on the 490

$\mathrm{n}=10 / 100(490)=49$

$\mathrm{n}=450+49=539$ caregivers

$\mathrm{n}=539$

This formula was adapted as a way to enable the researcher to determine the exact number of caregivers to choose from each sub district for inclusion in the study.

\subsection{Sampling Techniques and Procedures}

Multi stage sampling method was used for the study. First, the purposive sampling technique was used to select the Northern Region and Savelugu/Nanton and Bunkpurugu/Yunyoo Districts on the basis of their malnutrition prevalence rates. That is, the Savelugu/Nanton has the highest rate and the Bunkpurugu/Yunyoo having the lowest rate of malnutrition in the Northern Region of Ghana according to the High Impact Rapid Delivery (HIRD) Supplementary Survey 2007 (GSS, 2007; GHS, 2016). 
Simple random technique was used to select communities or clusters from the list of all communities/clusters in the two districts. In all ten (10) clusters were selected from the two districts, with five from each district. Ten clusters were selected in order to obtain a large sampling frame for further selection of respondents. Finally, the proportional stratified sampling technique was applied to select caregivers with their children in each cluster for inclusion in the study. From the Child Welfare Clinics, there are complete lists of all children with their primary caregivers which makes it the best to apply the proportional stratified sampling technique in each cluster of each district.

\subsection{Data Analysis}

Data was analysed using the Statistical Package for Social Sciences (SPSS) version 21.0. The results are presented in tables and graphs for easy description. The odds ratio, Chi Square Test and P Values were used to test the level of significance in the data.

Weight-for-age (defined as a child's weight given his or her age); Height-for-age (defined as a child's height given his/her age) and finally Weight-for-height (defined as a child's weight given his/her height) are the three common anthropometric measures of malnutrition and the nutritional status of under-five-year-old children.

These indicators were calculated from the data set for standardisation and comparison of children with the same age bracket in the population, Weight-for-age (WAZ), Height-for-age (HAZ) and Weight-for-height (WHZ) are typically expressed as a Z-score using the WHO standardisation method $(\mathrm{WHO}, 2006)$. Z-score $=($ Observed value) - (Median value of the reference value)/(Standard deviation of the reference population) The Z-scores provide basis for standardisation of indicators for nutritional status and long life health and cognitive development of children (UNICEF, WHO \& World Bank, 2011).

Data of the standardised anthropometric measures are used in formulating policy targets and evaluating the nutritional and health programmes for children under five years. According to the WHO (2006) stunting is heightfor-age below -2 standard deviation (SD), whilst, underweight is weight-for-age below $-2 \mathrm{SD}$, with wasting being weight-for-height below $-2 \mathrm{SD}$ and Overweight is weight-for-height above $+2 \mathrm{SD}$.

\subsection{RESULTS AND DISCUSSIONS}

This section presents findings and discussions of analysis of survey data obtained from the Savelugu/Nanton Municipality and Bunkpurugu/Yunyoo District of the Northern Region of Ghana.

\subsection{Socio-Demographic Characteristics of Caregivers}

A total of 495 study participants were sampled during the study period from 10 clusters. These clusters were; Savelugu, (24.2\%), Nanton, (8.5\%), Pong-Tamale, (10.3\%), Diare, (9.3\%), Tampiong, (6.7\%), Bunkpurugu, (11.5\%), Binde, (13.1\%), Nakpanduri, (6.9\%), Nasuan, (5.7\%), and Yunyoo, (3.8\%). These clusters where selected from two districts in the Northern Region namely; Savelugu/Nanton made up of $(54.5 \%)$ study participants and Bunkpurugu/Yunyoo made up of (45.5\%) respondents.

The mean age of the respondents was $21.4 \pm 8.3$ (mean $\pm \mathrm{SD}$ ). The modal age group for the study was (31-40) years constituting 39.2\% of the respondents. There was a married preponderance. Majority of the study participants representing $77 \%$ had at least some form of formal education whilst a relatively smaller number representing $23 \%$ indicated they had no form of any formal education.

Analyses further revealed that half of the respondents representing 55.8\% were described as the Mole Dagbani comprising the Mamprusis, Dagombas and the Nanumbas. Majority of the respondents were also Bimobas representing $40.4 \%$ of the total study participants. Others identified ethnic groups in the study included; Konkomba (1.2\%) and Akans (2.6\%). From the analysis, (58.6\%) were sampled from the peri-urban area, $(22.2 \%)$ were sampled from the rural communities whilst (19.2\%) were sampled from the urban areas. From the analysis, $49.7 \%$ were salaried workers whilst $46.7 \%$ and $3.6 \%$ respectively were unemployed and farmers respectively. Among those with reliable sources of their own personal income, 56\% earned between Ghc. 1000- Ghc. 2000 per annum, 20\% earned between Ghc. 2001- Ghc. 4000 per annum, whilst 24\% earned above Ghc. 4001 per annum. The analyses of the socio-demographic characteristics of the respondents are shown in Table 1.

Analyses of predictors of feeding practices were modeled after controlling for confounding factors. Confounding factors were controlled by matching and randomisation. Analyses revealed that respondents with formal education were 6 times more likely to breastfeed their child immediately after birth or within one hour after birth compared with their counterparts who had informal education $(\mathrm{OR}=6.0 ; 95 \% \mathrm{CI}$ : 1.9- 12.8; $\mathrm{P}=0.004)$. This analysis suggests that educated women may be informed by the benefits of early initiation of breastfeeding. The study also revealed that women who were married were 7 times more likely to feed the child by themselves, allow relatives to feed the child or caregiver to feed the child as compared to women who were single $(\mathrm{OR}=7.0 ; 95 \%$ 
CI:1.0-20.1; $\mathrm{P}=0.003)$.

\begin{tabular}{lll}
\hline Variable & Frequency & Percentage \\
\hline Age (years) & 18 & \\
$10-19$ & 156 & 3.6 \\
$20-29$ & 194 & 31.5 \\
$30-39$ & 127 & 39.2 \\
$40-49$ & & 25.7 \\
Marital status & 42 & \\
Never married & 419 & 8.5 \\
Married & 5 & 84.6 \\
Separated & 29 & 1.0 \\
Divorced & & 5.9 \\
Educational level & 381 & \\
Formal & 114 & 77.0 \\
Informal & & 23.0 \\
Occupational status & 231 & 46.7 \\
Unemployed & 18 & 3.6 \\
Farmer & 246 & 49.7 \\
Salaried workers & & \\
Type of residential & 95 & 19.2 \\
Urban & 290 & 58.6 \\
Peri-urban & 110 & 22.2 \\
Rural & & \\
\hline Sourc: & & \\
\hline
\end{tabular}

Source: Field Survey, 2017

Table 1. Socio-Demographic Characteristics of Respondents

\subsection{Socio-Demographic Characteristics of Children}

Caregivers' child's bio-data was also assessed to assist in determining the nutritional status of their children with the help of their anthropometric information. From the results, majority of the children were predominantly boys. All children who met the study inclusion criteria, their dates of births were verified by checking on the National Health Insurance card, the immunisation card, birth certificates and baptismal cards. For those whose cards were not available at the time of the research the researcher had no option but to rely on the services of the primary caregiver who in most times are even considered as key informants with respect to the child's information in the absence of their mothers.

And in this case, primary caregivers were very instrumental in providing the date of birth for the children. $6.1 \%$ of children's dates of birth were provided by their primary caregivers. In the extreme cases where caregivers were not able to provide an exact date of birth of the child, the use of the seasons and notable events in Ghana assisted in the date of birth of the child. In this scenario, findings revealed that only $3 \%$ respondents claimed they did not know the dates of birth of their babies and were probed to use the traditional calendar to estimate their dates and months of birth . $90.9 \%$ of the children had attended Child Welfare Clinics, with most children taking all the immunisation schedules. Nearly all the respondents $97.8 \%$ said their children had taken the Vitamin A Supplementation. 


Iㅏㅌㅏ.

\begin{tabular}{lcc}
\hline \multicolumn{1}{c}{ Variables } & Frequency & Percentage \\
\hline Sex & 272 & \\
Male & 223 & 54.9 \\
Female & & 45.1 \\
Age of child in Months & 30 & \\
$6-8$ & 67 & 13.1 \\
$9-11$ & 111 & 22.4 \\
$12-17$ & 140 & 28.3 \\
$18-23$ & 147 & 29.7 \\
$24-36$ & & \\
Sources of date of birth & 450 & 90.9 \\
Card & 30 & 6.1 \\
Caregiver & 15 & 3.0 \\
Landmark events & 310 & 62.6 \\
Child \& immunization & 180 & 36.4 \\
Yes & 5 & 1.0 \\
No & & \\
Do not know & 363 & 73.3 \\
Child \& meningitis & 91 & 18.4 \\
Yes & 41 & 8.3 \\
No & & \\
Do not know & 484 & 97.8 \\
Child \& vitamin A supp. & 10 & 2.0 \\
Yes & 1 & 0.2 \\
No & & \\
Do not know & &
\end{tabular}

Source: Field data, 2017

Table 2. Socio-Demographic Characteristics of Children

\begin{tabular}{lcc}
\hline Variable & Frequency & Percentage \\
\hline Weight of children & 300 & 60.6 \\
Normal & 112 & 22.6 \\
Underweight & 40 & 8.1 \\
Severe underweight & 43 & 8.7 \\
Overweight & & \\
Wasting status & 395 & 79.8 \\
Normal & 75 & 15.2 \\
Wasting & 25 & 5.0 \\
Severe wasting & & \\
Stunting status & 282 & 57.0 \\
Normal & 174 & 35.4 \\
Stunting & 38 & 7.6 \\
Severe stunting & &
\end{tabular}

Source: Field Survey, 2017

Table 3. Anthropometric data of children 


\subsection{Caregivers' Adherence to Breastfeeding Practices}

The practice of mothers and caregivers adhering to exclusive breastfeeding in a particular community depends on general perception of the people in the community about exclusive breastfeeding and what should be considered as child feeding practices. If women and caregivers are aware of the benefits of adequate breastfeeding for them and their infants, they may likely practice it. Most women do not practice exclusive breastfeeding as recommended probably because they are ignorant of the benefit associated with such practice or are also ill informed of the advantages of exclusive breastfeeding.

Results from the study revealed that majority of the respondents representing $96 \%$ stated that they had ever practiced breastfeeding. Exclusive breastfeeding if effectively practiced has the enormous benefits for the child and the mother. This finding from the study supports the study done by Gewa and Leslie (2009) where the report revealed that $49 \%$ of babies are breastfed. Same can be said for Sreedhara and Banapurmath (2013), where the prevalence of exclusive breastfeeding for six months was $68 \%$ among infants in five urban slum areas in central Karnataka. Similar findings were reported by Ubeysekara et al. (2015), where prevalence of exclusive breast feeding for 6 months was $88.8 \%$.

Likewise, Gandhi et al. (2014) found that, around one-third mothers had given exclusive breast-feeding to their babies for 6 months in rural area of Navsari District in India. Again, this results is in conformity with the finding of Sreegiri et al. (2015), where majority (88.4\%) of children received exclusive breast feeding, and the remaining (11.6\%) children received artificial feeding along with breast milk in the first 6 months of age. More so, Ndanu (2013) found that exclusive breastfeeding rate was $69.4 \%$ among mothers in selected women's prison in Kenya, and they continued breastfeeding at 1 year $(88.5 \%)$ and at 2 years (52.2 \%). Even so, Sultana et al. (2014) found that, most $(82.7 \%)$ mothers offered exclusive breastfeeding to their children and breastfeeding was continued for $98 \%$ of the children. Even so, Muslimatum and Wiradnyani (2016) found that, all of the children in their study, except one, were ever breast-fed.

On the contrary, Safari et al. (2013) conducted a study on infants in Morogoro Municipality in Tanzania and found that, no child in the $\geq 4$ months old was exclusively breastfed. Same was recorded by Manangaet al. (2014), where low breastfeeding rate was observed among mothers in Bangang Rural Community in Cameroon, hence Mananga et al., (2014) concluded that exclusive breastfeeding was scarce by those mothers.

It is important to mention that the effective practice of exclusive breastfeeding has the potential to provide sources of energy and nutrients in children aged 6 to 23 months. It can provide half or more of a child's energy needs between the ages of 6 and 12 months. Also it is a critical source of energy and nutrients during illness, and reduces mortality among children who are malnourished. And more importantly, the practice of exclusive breastfeeding contributes to the babies being less likely to be overweight/obese in adolescent life. The study also revealed that about $16.8 \%$ respondents indicated that they practiced breastfeeding for more than 8 months. This result is similar to that of Sawadogo et al. (2011) that, if mothers are well informed on what to do especially with regards to exclusive breastfeeding, then they are more likely to practice it with minimal coercion from the health workers.

\begin{tabular}{lcc}
\hline Variable & Frequency & Percentage \\
\hline Duration of exclusive breastfeeding & 75 & 15.8 \\
4 months & 120 & 25.3 \\
6 months & 200 & 42.1 \\
8 months & 80 & 16.8 \\
More than 8 months & & 44.4 \\
When child was put to breast after delivery & 220 & 37.4 \\
Within the first hour & 185 & 18.2 \\
After the first hour & 90 & 94.9 \\
Do not know & & 5.1 \\
Colostrum & 470 & 87.7 \\
Yes & 25 & 12.3 \\
No & & 37.4 \\
Breast milk and time of feeding & 434 & 62.6 \\
Yes & 61 & 22.0 \\
No & & \\
Ynfant formula & 185 & \\
No & 310 & \\
Milk & & \\
Yes & 109 & \\
\hline
\end{tabular}




\begin{tabular}{lcc}
\hline No & & 78.0 \\
Fruit juice & 386 & 26.9 \\
Yes & 133 & 73.1 \\
No & 362 & 51.7 \\
Tea & & 48.3 \\
Yes & 256 & 57.0 \\
No & 239 & 43.0 \\
Carbonated drink & & \\
Yes & 282 & 36.6 \\
No & 213 & 63.4 \\
Traditional medicine & & 36.4 \\
Yes & & 63.6 \\
No & 181 & \\
Bottle with nipple & 314 & \\
Yes & & \\
No & 180 & 315 \\
\hline Source: Field Survey
\end{tabular}

Source: Field Survey, 2017

Table 4. Breastfeeding Practices of Caregivers

\subsection{Breastfeeding Practices and Nutritional Status of Children}

From the results, $(44.4 \%)$ of the respondents indicated that they put their children to the breast immediately after delivery. This is in consonance with the findings of Gandhi et al. (2014), where about half of the mothers had initiated breastfeeding within 1 hour of birth. Similar finding was recorded by Sultana et al. (2014), where of the mothers, $67.3 \%$ initiated breastfeeding within one hour of birth.

Again, the results revealed that, respondents knew the importance of colostrums to their children. From the results as high as $94.8 \%$ stated that they gave colostrums to their babies after delivery. This is consistent with the findings of Gandhi et al. (2014) in rural area of Navsari District in India, where about $90.9 \%$ mothers fed colostrum to their child. Likewise, Safari et al. (2013) revealed that majority (92\%) of the respondents (mothers in Morogoro Municipality in Tanzania) gave colostrum to infants although more than $50 \%$ did not know its benefits.

On the contrary, this finding is at variance with the findings made by Jones (2003) were mothers and caregivers in Benin stated that colostrums was not good for their babies especially after delivery.

From the results on Exclusive Breastfeeding (EBF) and Nutritional Status of Children shown in Table 5, there was a relationship between wasting status of children and the duration of EBF. From the results, it was revealed that $44 \%$ of the babies having been breastfed for 8 months were found to be normal for wasting status as per the WHO standard. This finding from the study is similar to the study done by Sreedhara and Banapurmath (2013), where wasting was found to be significantly associated with the duration of EBF.

Again, findings from the study showed that, there was a relationship between underweight status of children and the duration of EBF. The results showed that, $36.2 \%$ of the children had normal weights. This finding from the study disagrees with the study by Ubeysekara et al., (2015) where the weight status of children was found not to be associated with the duration of EBF.

From the results, there was a significant relationship between stunting status of children and the duration of EBF. Thus, children who were exclusively breastfed at six months normal weights for stunting as shown in Table 5. This finding from the study agrees with the study by Sreedhara and Banapurmath (2013) where stunting status of children was found to be associated with duration of EBF. 


\begin{tabular}{|c|c|c|c|c|c|}
\hline \multirow[t]{2}{*}{ Nutritional status } & \multicolumn{5}{|c|}{ Duration of BF (months) in percentage } \\
\hline & 4 & 6 & 8 & $8<$ & $\mathrm{P}$ values \\
\hline Wasting status & & & & & 0.000 \\
\hline Normal & 12.3 & 33.7 & 44.0 & 10.0 & \\
\hline Wasting & 44.9 & 22.1 & 13.7 & 19.3 & \\
\hline Severe wasting & 33.8 & 21.9 & 33.2 & 11.1 & \\
\hline Underweight status & & & & & 0.000 \\
\hline Normal & 16.1 & 36.2 & 21.3 & 26.4 & \\
\hline Underweight & 53.3 & 22.1 & 13.7 & 10.9 & \\
\hline Severe underweight & 43.9 & 22.3 & 22.5 & 11.3 & \\
\hline Overweight & 22.5 & 33.4 & 22.9 & 21.2 & \\
\hline Stunting status & & & & & 0.000 \\
\hline Normal & 31.6 & 43.2 & 14.2 & 11.0 & \\
\hline Stunting & 23.6 & 12.3 & 18.8 & 45.3 & \\
\hline Severe stunting & 22.4 & 33.6 & 22.2 & 21.8 & \\
\hline
\end{tabular}

Source: Field Survey, 2017

Table 5. Breastfeeding Practices and Nutritional Status of Children

\subsection{Caregivers Adherence to Introduction of Solid/Semi-solids and Nutritional Status of Children}

Introduction of complementary foods to babies is often accompanied by stress and ill health especially if it is not done well. This is when the food is not tailored to the child's needs and mothers and caregivers not adhering to child feeding practices deprive the child of the highly required nutrients.

Finding from the study revealed that few $5.1 \%$ of the caregivers introduced complementary foods to their children after breast feeding for a reasonable period of time with most of them saying immediately after delivery. This is consistent with the results of (Sultana et al., 2014), where the early introduction (before 6 months) of complementary feeding to children aged 6-23 months was less $(16.9 \%)$.

On the other hand, this discovery is at variance with the results of Sreedhara and Banapurmath (2013), where majority $(72 \%)$ of infants at one year were receiving thick complementary foods and $61 \%$ of infants at one year were fed adequate amount of complementary foods .Likewise, Sreegiri et al. (2015) found that, in $74 \%$ of the children (in Paderu Division in Visakhapatnam), introduction of solid and semi-solid feeding was in the 6th month of their age whereas in $26 \%$ of children it was delayed beyond 6 months.

Similar finding was recorded by Mananga et al. (2014), where 50.39\% of mothers in Bangang Rural Community in Cameroon, introduced complementary foods before six months. More so, Muslimatum and Wiradnyani (2016) disclosed from their study that, complementary foods were introduced when the children were 6 months old $(43 \cdot 2 \%)$, younger than 6 months $(41 \cdot 9 \%)$ or older than 6 months $(14 \cdot 9 \%)$.

Early introduction of complementary feeding to children does not necessarily promote growth and development but encourages other diseases such as diarrhoea and may not even encourage children to take enough breast milk. Early introduction of solid foods to children by caregivers has always been linked to a number of factors. Prominent among them has always been the fact that sometimes due to work pressure caregivers may not be available and the expressed breast milk may not be tasty again after sometime for the baby. This often compelled caregivers to give them solid foods. Grandparents especially grandmothers also have an influence with respect to the feeding practice of the child especially at certain times.

\begin{tabular}{lcc}
\hline Variable & Frequency & Percentage \\
\hline Age of introduction of complementary food & & 5.1 \\
Immediately after birth & 25 & 28.9 \\
Three months after birth & 143 & 34.8 \\
Four months after birth & 173 & 25.5 \\
Six months after birth & 126 & 5.7 \\
After six months of birth & 28 & 69.5 \\
Solid food & & \\
Yes & 344 & 30.5 \\
No & 151 & 98.0 \\
Foods made from grains & & 2.0 \\
Yes & 485 & \\
Food made from roots/tubers & 10 & \\
Yes & & \\
No & 461 & 6.9 \\
\hline Sour: Field Survey 2017 & 34 & \\
\hline
\end{tabular}

Source: Field Survey, 2017

Table 6. Introduction of solids, semi-solids/family foods 
Caregivers may be coerced by other relatives to do what they are instructed to do. Finding also showed that most respondents $(34.8 \%)$ stated that they introduced solid foods to their children four months after birth, and this is consistent with results of Sreedhara and Banapurmath (2013), where hundred infants in five urban slum areas in central Karnataka were studied. Sreedhara and Banapurmath (2013) found higher prevalence of malnutrition in infants in whom complementary feeding was initiated before six months $(\mathrm{P}<0.001)$, in whom complementary feeding was inadequate $(\mathrm{P}<0.001)$ or inappropriate $(\mathrm{P}<0.001)$.

On the contrary, this finding from the study is at variance with the WHO (2006) report which made it clear that children should be introduced to complementary feeding after six months of life. However, the results appear to be similar to the findings made by Engebretsen et al. (2007) where children were introduced to solid foods before the age of 4 months in Ethiopia. The place of residence also affects the age of introduction of solid foods, with urban mothers introducing these at an earlier average age than mothers residing in rural regions.

This could be due to the fact that mother's place of residence could influence how children should be breastfed for a longer duration and hence delay the introduction of foods/fluids. Mothers/caregivers commonly give their babies other substances such as water with sugar, butter and family food, in addition to breast milk. Complementary foods are introduced fairly early in a child's life with many infants and young children in subSaharan Africa subsisting on porridge prepared from staples, accompanied with vegetables and legumes, and only occasionally, animal foods. It is therefore not surprising that from the results nearly all the respondents $(98 \%$ and 93.1\%) stated that the solid food they gave to their children were made from grains and roots/tubers respectively. It is therefore, paramount that feeding and child care during this period be optimised, focusing mainly on frequency of feeding, the energy density of the foods, diversity of foods in the diet, the safety of the foods and the feeding processed.

From the results of this study, there was no any significant relationships of the time of introduction of solid/semi solid foods are the nutritional status of children as shown in Table 7.

\section{Variable Age at which complementary foods are introduced (in months) P value}

\begin{tabular}{|c|c|c|c|c|c|c|}
\hline & After birth & three & Four & six & $\begin{array}{l}\text { More } \\
\text { than six }\end{array}$ & \\
\hline Underweight & & & & & & 0.213 \\
\hline Normal & 4.3 & 26.0 & 37.3 & 27.0 & 5.3 & \\
\hline Underweight & 2.7 & 37.5 & 27.7 & 25.0 & 7.1 & \\
\hline Severe Underweight & 2.5 & 27.0 & 45.0 & 20.0 & 5.0 & \\
\hline Overweight & 9.3 & 30.2 & 34.9 & 20.9 & 20.9 & \\
\hline Wasting & & & & & & 0.110 \\
\hline Normal & 4.3 & 29.1 & 35.4 & 26.3 & 4.8 & \\
\hline Wasting & 4.0 & 34.7 & 34.7 & 18.7 & 8.0 & \\
\hline Severe wasting & 4.0 & 12.0 & 40.0 & 32.0 & 12.0 & \\
\hline Stunting & & & & & & 0.163 \\
\hline Normal & 5.7 & 29.8 & 31.2 & 28.4 & 5.0 & \\
\hline Stunting & 1.7 & 29.9 & 41.4 & 20.7 & 6.3 & \\
\hline Severe wasting & 5.1 & 20.5 & 41.0 & 25.6 & 7.7 & \\
\hline
\end{tabular}

Field Survey, 2017

Table 7. Complementary Feeding Practices and Nutritional Status of Children in Percentages

\subsection{CONCLUSIONS AND RECOMMENDATIONS}

Generally, feeding practices of caregivers was poor and that affected the nutritional status of children in the study area. According to the WHO classification of malnutrition by prevalence ranges, underweight was high among children. For stunting levels, the study concludes that the rate was very high according to the WHO standards. Wasting levels were also considered to be very high according to the WHO classifications and overweight was emerging as a potential for worry by the study.

Breastfeeding practices were poor and these affected the nutritional status of children in the study area. For example, duration of breastfeeding was positively related to the underweight, wasting and stunted statuses of children in the study area. 
Furthermore, this study revealed that adherence of caregivers regarding the introduction of solids at six months was inappropriate. For instance, caregivers introduced solids/family foods before six months and the age at which caregivers introduced solids/semi solids to their children did not influence the underweight, wasting and stunting statuses of children in the study area.

In many communities in rural Ghana, exclusive breastfeeding for 6 months remains relatively uncommon. It is possible that mothers who continue to exclusively breastfeed their infants to at least 6 months differ from those who do not, either in having a slower growing infant with lower energy requirements, higher breast milk volume production, or higher breast milk energy content. An enlightenment campaign in various languages centered on the benefits of exclusive breastfeeding could help improve practice. From the results, breastfeeding of children is virtually universal in the study communities, but exclusive breastfeeding of the kind that meets WHO/UNICEF standards was rare and low.

This study recommends as a matter of urgency to the GHS nutrition unit and its partners in addressing underlying factors to inappropriate feeding practices among caregivers with children six months and upwards. This could be achieved by up scaling its educational campaigns on better nutrition for better future.

\section{ACKNOWLEDGEMENTS}

I acknowledge Prof. Akwasi Kumi-Kyereme and Prof. Eugene Darteh for their guidance and supervisory roles on my Doctor of Philosophy Course at the Department of Population and Health, University of Cape Coast, Ghana. I also acknowledge the Directors of the Regional and District Health Directorates of the Northern Region, the Savelugu/Nanton Municipality and Bunkpurugu/Yunyoo District for their diverse supports especially in providing secondary data on nutrition prevalence which assisted the researcher to calculate the sample size for the study and finally, I acknowledge Ali Mary Maaka, the Nutritionist of the Savelugu Municipal Hospital who assisted in weighing children and data collection; Gideon Nandam, and Laar Michael who also assisted in data collection on the field and Baba Atubiga for data entry and analysis.

\section{References}

Darapheak, C., Takano, T., Kizuki, M., Nakamura, K \& Seino, K. (2013). Consumption of animal source foods and dietary diversity reduce stunting in children in Cambodia. International Archives of Medicine. Vol 6.

Engebretsen, I. M. Nankabirwa, V. Doherty, T. Diallo, A. H. Nankunda, J. \& Fadnes, L. (2014). Early infant feeding practices in three African countries: the PROMISE-EBF trial promoting exclusive breastfeeding by peer counsellors. International Breastfeed Journal, 9: 19.

Gandhi, J.S., Godara, N., Modi, A., \& Kantharia, S. (2014). Impact of feeding practices on nutritional status of children in rural area of Navsari District. International Journal of Medical Science and Public Health. 3(11):1338-1342.

Gewa, C. A. \& Leslie, T. F. (2015). Distribution and determinants of young child feeding practices in the East African region: Demographic health survey data analysis from 2008-2011. Journal Health Population Nutrition, 34(6): 1-14.

Ghana Health Service (GHS). (2016). Northern Region Annual Nutritional Reports. (Unpublished)

GHS (2007). Vitamin A deficiency in Ghana. Ghana Food Fortification Baseline Survey.

Ghana Statistical Service (GSS) (2006). Ghana Multiple Indicator Cluster Survey. Final Report, Accra, Ghana.

GSS (2007). The High Impact Rapid Delivery (HIRD) Supplementary Survey (District MICS), Final Report. Accra, Ghana.

GSS (2011). Ghana Multiple Indicator Cluster Survey with Enhances Malaria Module and Biomarker, Final Report. Accra, Ghana.

Ghana Statistical Service (GSS). (2014). Ghana Health Service (GHS) \& ICF Macro. 2015. Ghana Demographic and Health Survey 2014. Accra; GSS, GSS, and ICF Macro.

Jones, G. (2003). How many child deaths can we prevent this year? (Child Survival Series). The Lancet. Vol. 362.

Mananga, M. J., Kana-Sop, M.M., Nolla, N. P., Ekoe, T \& Gouado, I.G (2013). Feeding Practices, Food and Nutrition Insecurity of infants and their Mothers in Bangang Rural Community, Cameroon. Journal of Nutrition and Food Science. 4:264. doi:10.4172/2155-9600.1000264

Muslimatun, S. \& Wiradnyani, L. A (2016). Dietary diversity, animal source food consumption and linear growth among children aged 1-5 years in Bandung, Indonesia: a longitudinal observational study. British Journal of Nutrition.1:S27-35. doi: 10.1017/S0007114515005395. Epub 2016 Jan 28.

Ndanu, M.M (2013). Feeding Practices and Nutritional Status of Children aged 0-59 months accompanying Incarcerated Mother's in selected Prisons in Kenya. (Unpublished). Available at http://ir-library.kuac.ke/handle/123456789/7485. Kenyatta University Institutional Repository.

Nishani, H. Ubeysekara, L. Renuka, J. Champa, J. \& Wijesinghe, M. (2015). Nutritional status and associated feeding practices among children aged 6-24 months in a selected community in Sri Lanka: A cross sectional study, 3(2-1): 15-23. 
Safari, J.G, Kimambo, S.C. \&Lwelamira J.E (2013). Feeding practices and nutritional status of infants in Morogoro Municipality, Tanzania. Tanzanian Journal of Health Research. 15(3):178-85.

Sawadogo, P. S. Martin-Prevel, Y. \& Savy, M. (2006). An infant and child feeding index is associated with nutritional status of 6 to 23 month old, children in rural Burkina Faso. Journal Nutrition. 136:656-63.

Spinks, T. \& Hamilton, K. (2015). Investigating key beliefs guiding mothers' dietary decisions for their 2-3 year old. Appetite. 89:167-74.

Sreedhara \& Banapurmath (2013). A study of nutritional status of infants in relation to their Complementary Feeding Practices. Current Padiatric Research; 18 (1):39-41.

Sreegiri, A. Birch, W. Tareeen, P. and Farett, D. (2015). Complementary feeding, and material decision making in a rural east Africa pastoral population. Journal of Human Lactation.

Sultana, S., Hoque, A \& Saleh, F. (2014). Infants and Young Children Feeding Practices andc Nutritional Status in Kapasia and Gazipur Districts. Journal of Human Nutrition and Food Science. 2(2):1028.

Ubeysekara, H. N., Jayathissa, R., \& Wijesinghe, J.C. (2015). Nutritional Status and associated feeding practices among children aged 6-24 months in selected Community in Sri Lanka: A cross sectional study. European Journal of Preventive Medicine. 3(2-1): 15-23.

UNICEF (2014). Global database. Infant and young child feeding. IYCF Unit, Nutrition Section, UNICEF New York.

UNICEF-WHO-World Bank (2013). Levels and Trends in Child Malnutrition. Joint Child Malnutrition Estimates. (UNICEF, New York; WHO, Geneva; the World Bank, Washington DC.)

World Health Organisation (WHO) (2006). Multicentre Growth Reference Study Group. WHO Child Growth Standards: Length/height-for-age, weight-for-age, weight-for-length/height, and body mass index-forage: Methods and development. Geneva.

World Health Organisation (WHO). (2014). World Health Statics. WHO; Geneva, Switzerland. 